Regular article

\title{
Two stages of treatments for upgrading bleached softwood paper grade pulp to dissolving pulp for viscose production
}

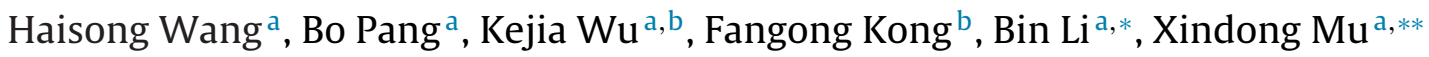 \\ a Key Laboratory of Biobased Materials E Qingdao Engineering Research Center for Bioenergy and Biomaterials, Qingdao Institute of Bioenergy and \\ Bioprocess Technology, Chinese Academy of Sciences, Qingdao, Shandong 266101, China \\ ${ }^{\mathrm{b}}$ Key Laboratory of Paper Science and Technology of Ministry of Education, Shandong Polytechnic University, Ji'nan, Shandong 250353, China
}

\section{A R T I C L E I N F O}

\section{Article history:}

Received 17 July 2013

Received in revised form 30 October 2013

Accepted 23 November 2013

Available online 1 December 2013

\section{Keywords:}

Dissolving pulp

Biomass

Enzyme

Alkaline peroxide

Biopolymers

Biofuels

\begin{abstract}
A B S T R A C T
To convert bleached softwood paper grade pulp into dissolving pulp for viscose application, two stages of treatments consisting of enzymatic treatment and alkaline peroxide treatment were investigated. It was found that high reactivity (about $80 \%$ ) of pulp could be achieved by endoglucanases (EG)-rich industrial cellulase treatment, and the $\alpha$-cellulose content as well as the viscosity of enzymatically treated pulp can be further adjusted by the alkaline peroxide treatment with certain dosages of $\mathrm{NaOH}$ and $\mathrm{H}_{2} \mathrm{O}_{2}$ to finally meet the quality requirements of dissolving pulp. The resulting pulp with $68.7 \%$ of reactivity, $92.1 \%$ of $\alpha$-cellulose content, and $506.9 \mathrm{~mL} / \mathrm{g}$ of pulp viscosity could be obtained after the two stages of treatments. The appropriate dosage of EG-rich cellulase was $300 \mathrm{IU} / \mathrm{g}$ bone dry pulp in the stage of enzymatic treatment, while the suitable dosages of $\mathrm{NaOH}$ and $\mathrm{H}_{2} \mathrm{O}_{2}$ were $9 \mathrm{wt} \%$ and 1 wt\%, respectively, in the stage of alkaline peroxide treatment.
\end{abstract}

(c) 2013 Elsevier B.V. All rights reserved.

\section{Introduction}

Dissolving pulp, which is generally produced by acidic sulphite pulping or pre-hydrolysis kraft process [1-3], is used to manufacture cellulose-derived products, such as regenerated fibers or films (e.g. viscose, Lyocell), cellulose ethers (carboxymethyl-, ethyl, methyl-celluloses), and cellulose esters (acetates, propionates, butyrates, nitrates) [4]. Compared with paper-grade pulp, dissolving pulp contains a higher content of cellulose (>90\%), lower content of hemicelluloses $(<4 \%)$, as well as trace levels of lignin, extractives and minerals [5].

In viscose process, which is the oldest commercial approach for the production of regenerated cellulose fibers, carbon disulfide $\left(\mathrm{CS}_{2}\right)$ is usually used as an etherification agent with highly negative environmental impact [6], despite the cellulose used is renewable and biodegradable material. It has been known that the use of high reactivity pulp can reduce the demand of $\mathrm{CS}_{2}$ in viscose process, improve the quality of end-products, and decrease processing costs $[7,8]$. Hence, various mechanical [9], chemical $[9,10]$ methods, and enzymatic treatments $[5,11]$ were conducted alone or in combination to improve cellulose reactivity. On the other hand, in the drive to reduce the process costs, the viability of upgrading

\footnotetext{
* Corresponding author. Tel.: +86 53280662725

** Corresponding author. Tel.: +86 53280662723 .

E-mail addresses: libin@qibebt.ac.cn (B. Li), muxd@qibebt.ac.cn (X. Mu).
}

paper-grade pulp to dissolving pulp has also been paid more attentions $[5,12,13]$.

However, increasing cellulose reactivity and accessibility is not an easy task as cellulose exhibits an extremely compact structure consisting of more-ordered (crystalline) and less-ordered (amorphous) regions formed by hydrogen bonds within the cellulose chains $[4,14]$. Other factors, such as hemicellulose content [15], the present of cellulose II (less reactive due to its antiparallel orientation than cellulose I with parallel chains) [9], the porosities of the cellulose structure, the solvent or reagent used, the internal surface, and the structure of the cellulose molecules can affect the cellulose reactivity as well $[4,8,16]$. In addition, conventional production of dissolving pulp caused serious environmental pollution, which is mainly due to the toxic effluent released from industries [17].

Recently, enzymatic treatment, specially the utilization of cellulases, has been considered as a very promising method for increasing cellulose reactivity [5-8,11-13], because enzymes are non-toxic and environmentally benign. Endoglucanases (EG), cellobiohydrolases ( $\mathrm{CBH}$ ) or exoglucanases, and $\beta$-glucosidases (BGL) or cellobiase are the three major groups of cellulases [18]. EG randomly cut the amorphous sites of cellulose, thus decreasing chain length and generating new chain ends. $\mathrm{CBH}$ attack the reducing or non-reducing ends of cellulose chains, releasing mainly cellobiose units, while BGL reacted with cellobiose, generating glucose units. Extensive studies $[1,5-8,10-12,19,20]$ focused on the utilization of the monocomponent EG to enhance cellulose reactivity. However, the cost of pure EG is much higher than that of EG-rich cellulases. 


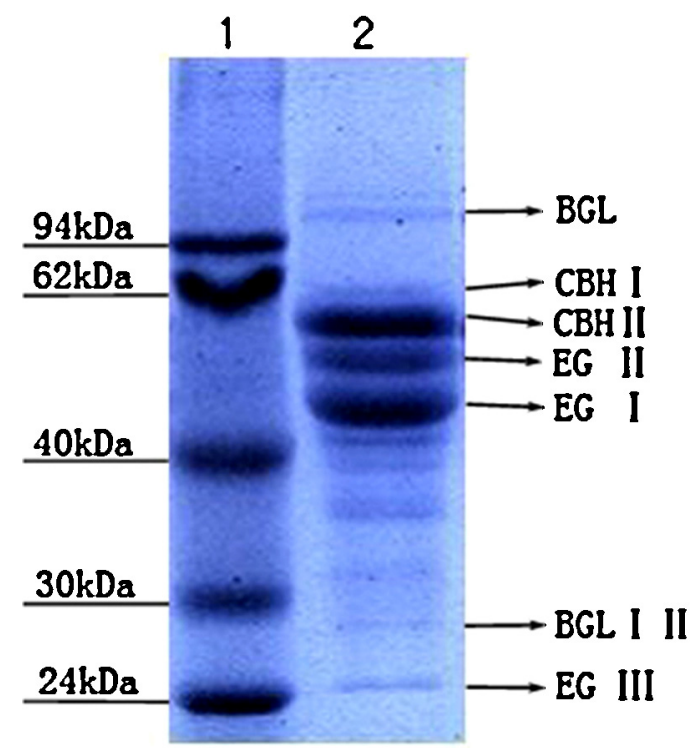

Fig. 1. SDS-PAGE of EG-rich cellulase (lane 1: Mw markers; lane 2: protein extract of cellulase).

Therefore, it is also a suitable approach to obtain high reactivity of cellulose by using EG-rich cellulases product in enzymatic treatment combined with other chemical treatments [21].

In this study, enzymatic treatment of bleached softwood papergrade pulp using an EG-rich industrial cellulase was conducted to improve the reactivity of cellulose. Subsequently, to well reach the quality of dissolving pulp, the enzymatically treated pulp was further adjusted by alkaline peroxide treatment for decreasing hemicellulose content and pulp viscosity, which is a typical approach used for pulp bleaching in pulping industry $[22,23]$. Meanwhile, the influence of treatment on pulp quality was evaluated by cellulose reactivity (based on Fock's method), $\alpha$-cellulose content, viscosity, and pulp yields.

\section{Experimental}

\subsection{Material}

The commercial elemental chlorine free (ECF)-bleached softwood Kraft paper-grade pulp (PGP) was kindly provided by a paper plant in East China. The properties of PGP on the basis of oven dry weight were: $\alpha$-cellulose content $85.1 \%$, hemicellulose content $14.7 \%$, ash content $1.2 \%$, lignin content $0.7 \%$, reactivity $32.8 \%$, and viscosity $916 \mathrm{~mL} / \mathrm{g}$. The reference sample obtained from a dissolving pulp mill in South China was the commercial softwood dissolving pulp with cellulose reactivity of $68.8 \%, \alpha$-cellulose content of $89.9 \%$, and viscosity value of $499.7 \mathrm{~mL} / \mathrm{g}$. Prior to treatments and analyses, the dried pulps were cut into $1 \mathrm{~cm} \times 1 \mathrm{~cm}$ pieces, kept in deionized water for $12 \mathrm{~h}$, and followed by the disintegration at $3 \mathrm{wt} \%$ consistency and 3000 revolutions. All treatments and analyses were carried out in duplicate in this study.

EG-rich cellulase was supplied by KDN pharmaceutical company (Qingdao, China). The enzymatic activity was $2450 \mathrm{IU} / \mathrm{g}$, and protein content was $27 \mathrm{mg} / \mathrm{mL}$. The protein composition was shown in Fig. 1. The identification of EG-rich cellulase was conducted in four steps: (1) the SDS-PAGE gel of EG-rich cellulase was running in a Bio-Rad Mini-PROTEAN Tetra Cell for about $1 \mathrm{~h}$ at a voltage of $120 \mathrm{~V}$; (2) after that, the gel was immersed in Coomassie blue (G$250)$ staining solution with slow agitation on a horizontal shaker for about 20-30 $\mathrm{min}$; (3) the gel was immersed in de-staining solution on the same shaker for about $20-30 \mathrm{~min}$; (4) changed the de-staining solution for 3-5 times until the bands could be seen clearly. Because each enzyme has its own molecular weight (Mw) which is different from others, the enzyme can be identified by comparing the Mw of each band (Lane 2 in Fig. 1) to the Mw of markers (Lane 1 in Fig. 1).

All other chemicals were of analytical grade and used as received without further purification.

\subsection{Enzymatic treatments}

Before enzymatic treatment, the PGP samples were adjusted to $\mathrm{pH} 6.5$ with phosphate buffer solution at $3 \mathrm{wt} \%$ pulp consistency. For a homogeneous distribution, the enzymes were firstly dispersed in the buffer and then added to the pulp. The enzymatic treatments were performed in sealed plastic bags in a water bath at $50{ }^{\circ} \mathrm{C}$ for $2 \mathrm{~h}$. Different enzyme dosages of $0,100,200,300,400$, and $500 \mathrm{IU} / \mathrm{g}$ (oven dry pulp) were investigated, respectively. During each test, the pulps were kneaded for $5 \mathrm{~min}$ in every $15 \mathrm{~min}$. After treatment, the enzymes were denatured by mixing with deionized water at $97^{\circ} \mathrm{C}$, and then washed with deionized water at room temperature. As a control, pulps were treated under identical conditions without enzyme.

\subsection{Alkaline peroxide treatments}

Alkaline peroxide treatment was performed using Parr 4560 reactor (Moline, Illinois, USA) at $97^{\circ} \mathrm{C}$ for $1 \mathrm{~h}$ with pulp consistency of $10 \mathrm{wt} \%$. The dosage of sodium hydroxide varied from 6 to $12 \%$ and the dosage of hydrogen peroxide ranged from 0 to $3 \%$. The use of the temperature at $97^{\circ} \mathrm{C}$ for the denaturing of enzyme and alkaline peroxide treatment is to simulate the temperature of the twin-screw extrusion process reported in our previous study [24]. Briefly, biomass entered the extruder via a feed inlet continuously with the screw speed of $325 \mathrm{rpm}$ (about $30 \mathrm{~s}$ of residence time in the extruder) and was crushed by a specially designed twin-screw extruder. During the extrusion process, great mechanical forces (frictional force and shearing force) were generated among the biomass fibers and the screws, leading to the fibrillation of fibers and the generation of a great amount of heat which can rapidly increase the temperature of biomass. Out of the extruder, the temperature of treated biomass was about $97^{\circ} \mathrm{C}$ and the biomass was preserved in a thermal insulation tank for $1 \mathrm{~h}$ to complete reactions. Therefore, if the alkaline peroxide treatment can be conducted at this temperature with good effectiveness, a continuous process (enzyme treatment + continuous alkaline peroxide treatment) can be developed in the future studies.

\subsection{Pulp quality analysis}

The reactivity of cellulose was determined according to the method described by Fock with slight modifications [25]. This method is time-consuming and needs reference data in multivariate calibration, but it can be performed with ordinary wet chemistry laboratory equipment [26]. The method consisted of two parts: 1) the preparation of viscose from dissolving pulp and the collection of regenerated cellulose; 2 ) the oxidation and titration of the regenerated cellulose. The detailed descriptions were reported in the previous studies [5,7], and the reactivity value was presented as the yield of regenerated cellulose.

The intrinsic viscosities $[\eta]$ of pulp samples were determined using capillary viscometer in cupriethylene-diamine (CED) solution at $25^{\circ} \mathrm{C}$ according to China International Standard (GB/T15481989) [27]. $\alpha$-Cellulose content, lignin content, and ash content were measured following TAPPI test standards, i.e. T 203, T 222, and $\mathrm{T} 211$, respectively. In addition, the analyses of total reducing sugar 


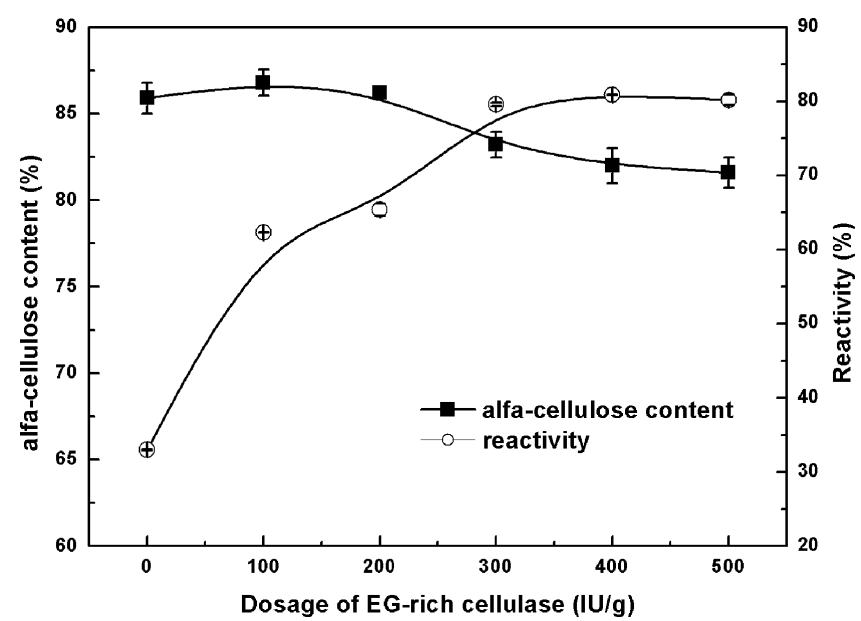

Fig. 2. Effect of dosage of EG-rich cellulase on cellulose reactivity and $\alpha$-cellulose content (enzymatic treatment conditions: $\mathrm{pH} 6.5 ; 3 \mathrm{wt} \%$ pulp consistency; $50{ }^{\circ} \mathrm{C}$ for $2 \mathrm{~h}$ incubation).

in spent liquor were performed by the use of 3,5-dinitrosalicylic acid (DNS) method.

\section{Results and discussion}

The processability of a dissolving pulp is typically determined by cellulose reactivity [4], which is defined as accessibility of the hydroxyl groups at $C_{6}$ and $C_{2} / C_{3}$ of the glucose monomer units to the reactants [11]. Furthermore, a high $\alpha$-cellulose content pulp with appropriate viscosity value is also one of the most important quality parameters of dissolving pulp. Thus, the aim of this work is to increase reactivity and $\alpha$-cellulose content, reduce viscosity, and simultaneously maintain a relatively high pulp yield.

\subsection{Effects of EG-rich cellulase treatments}

The effects of the dosage of EG-rich cellulase on cellulose reactivity and $\alpha$-cellulose content are presented in Fig. 2 . As can be seen, the $\alpha$-cellulose content decreased with the increase of cellulase dosage used. This was mainly due to the modification of cellulose by EG-rich cellulase attack [7,18,21], which was in agreement with the increment of reducing sugar in spent liquor after enzymatic treatment. The total reducing sugar increased from about $2.16 \mathrm{~g} / \mathrm{L}$ to $4.04 \mathrm{~g} / \mathrm{L}$ when the dose of EG-rich cellulase increased from $100 \mathrm{IU} / \mathrm{g}$ to $500 \mathrm{IU} / \mathrm{g}$ (Table 1 ). Correspondingly, the pulp yield reduced from about $94 \%$ to $86 \%$, and the viscosity decreased to approximately $530 \mathrm{~mL} / \mathrm{g}$, as exhibited in Fig. 3. This is because EG-rich cellulase contains a certain amount of $\mathrm{CBH}$ and BGL (Fig. 1), resulting in the degradation of small cellulose fragments. Thus, the component of $\mathrm{EG}, \mathrm{CBH}$ and BGL is a very important parameter. On the other hand, some variables (like temperature and $\mathrm{pH}$ ) may increase/decrease enzyme activities, as different enzymes have different optimal reaction conditions. Therefore, controlling reaction parameters (e.g. temperature and $\mathrm{pH}$ ) or adding suitable surfactants could adjust enzymes activities to a certain extent, but more tests are needed in the future to verify the effectiveness.

Fig. 2 also showed that, the reactivity improved significantly as the dosage of cellulase increased. About $80 \%$ of reactivity could be

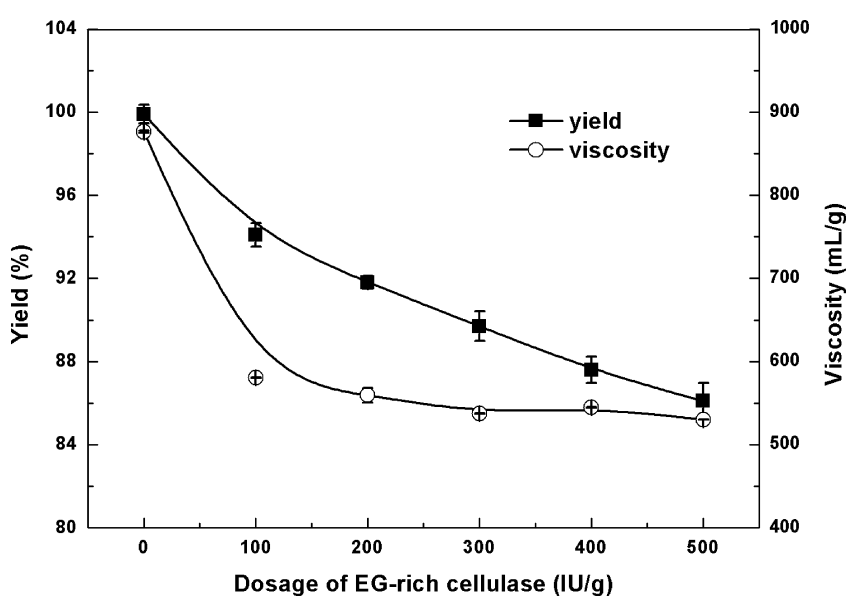

Fig. 3. Effect of dosage of EG-rich cellulase on pulp yield and viscosity (enzymatic treatment conditions: $\mathrm{pH} 6.5 ; 3 \mathrm{wt} \%$ pulp consistency; $50{ }^{\circ} \mathrm{C}$ for $2 \mathrm{~h}$ incubation).

achieved with the cellulase dose of $300 \mathrm{IU} / \mathrm{g}$, which was remarkably higher than that of the commercial dissolving pulp (68.8\%). This was mainly because of the chain cleavage at amorphous sites by EG cutting [5-7]. Nevertheless, the reactivity seemed some constant when the dosage of cellulase was over $300 \mathrm{IU} / \mathrm{g}$ (Fig. 2), which was probably due to the steric hindrance as the penetration of enzymes into the fibrils could be limited by the available surface areas $[8,19]$. This was in accordance with the minor change of viscosity at relatively high cellulase dosages, as presented in Fig. 3. However, despite the reactivity and pulp viscosity seemed not to be affected, there were still some drops (about 3\%) of pulp yield at high cellulase concentration (over $300 \mathrm{IU} / \mathrm{g}$ ). This was more likely due to that the small cellulose fragments were degraded by $\mathrm{CBH}$ and BGL in the EG-rich cellulase, and it was consistent with the increase of reducing sugar at higher enzyme dosages, e.g. about $1 \mathrm{~g} / \mathrm{L}$ increment of total reducing sugar in spent liquor could be obtained as the enzyme dose increased from $300 \mathrm{IU} / \mathrm{g}$ to $500 \mathrm{IU} / \mathrm{g}$ (Table 1 ). For the case of $300 \mathrm{IU} / \mathrm{g}$, the reducing sugar in spent liquor after enzymatic treatment was about $2.90 \mathrm{~g} / \mathrm{L}$, and this is about $10 \%$ of sugar recovery (based on the original dry pulp). Thus, such amount of reducing sugar can be recovered for further utilization (e.g. the production of many value-added products, such as biofuels and biochemicals) with the integrated biorefinery possibilities [28,29]. On the other hand, to inhibit the degradation of cellulose fragments, the activities of $\mathrm{CBH}$ and $\mathrm{BGL}$ could be lowered by adjusting reaction parameters.

Based on the results displayed above, the suitable dosage of EG-rich cellulase was $300 \mathrm{IU} / \mathrm{g}$ oven dry pulp for the enzymatic treatment at $50{ }^{\circ} \mathrm{C}$ for $2 \mathrm{~h}$ with the pulp consistency of $3 \mathrm{wt} \%$. Under such conditions, the reactivity and pulp viscosity after enzymatic treatment were $79.9 \%$ and $537.3 \mathrm{~mL} / \mathrm{g}$, respectively, while the $\alpha$-cellulose content (85.2\%) was not high enough, compared with the reference sample (commercial dissolving pulp with $89.9 \%$ $\alpha$-cellulose). This is due to the fact that the large amount of hemicellulose still remained in the enzymatically treated pulps (hemicellulose content 10.2\%). Consequently, the subsequent alkaline peroxide treatment was carried out to further adjust the $\alpha$-cellulose content and pulp viscosity to meet the requirements of dissolving pulp.

Table 1

Reducing sugar concentration in spent liquor after enzymatic treatment ${ }^{\mathrm{a}}$.

\begin{tabular}{|c|c|c|c|c|c|c|}
\hline Dosage of EG-rich cellulase (IU/g) & 0 & 100 & 200 & 300 & 400 & 500 \\
\hline Reducing sugar in spent liquor $(\mathrm{g} / \mathrm{L})$ & 0 & 2.16 & 2.40 & 2.90 & 3.65 & 4.04 \\
\hline
\end{tabular}

a Enzymatic treatment conditions: $\mathrm{pH} 6.5 ; 3 \mathrm{wt} \%$ pulp consistency; $50^{\circ} \mathrm{C}$ for $2 \mathrm{~h}$ incubation. 


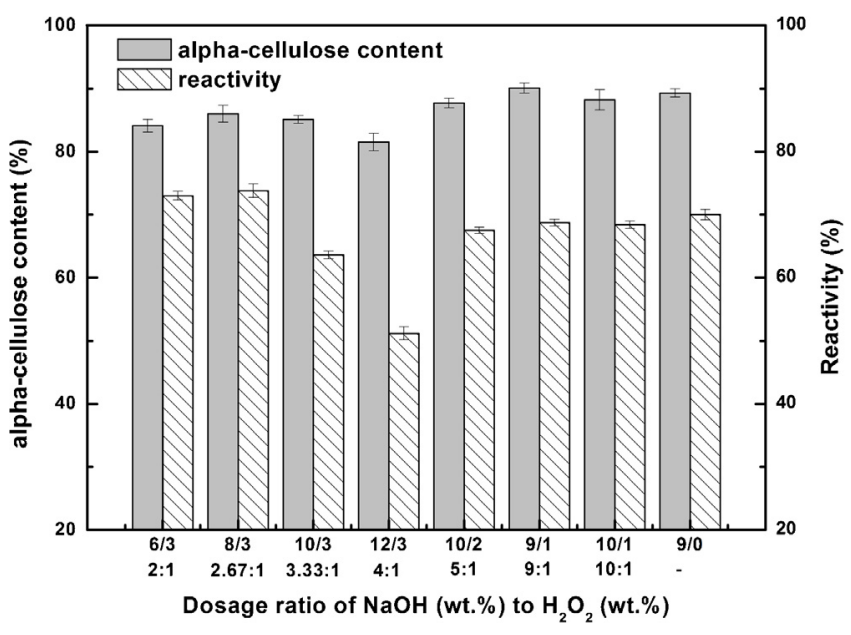

Fig. 4. Effects of alkaline peroxide treatment with different dosages of $\mathrm{NaOH}$ and $\mathrm{H}_{2} \mathrm{O}_{2}$ on reactivity and $\alpha$-cellulose content (alkaline peroxide treatment was conducted at $97^{\circ} \mathrm{C}$ for $1 \mathrm{~h}$ with $10 \mathrm{wt} \%$ of pulp consistency and the certain dosages of $\mathrm{NaOH}$ and $\mathrm{H}_{2} \mathrm{O}_{2}$ ).

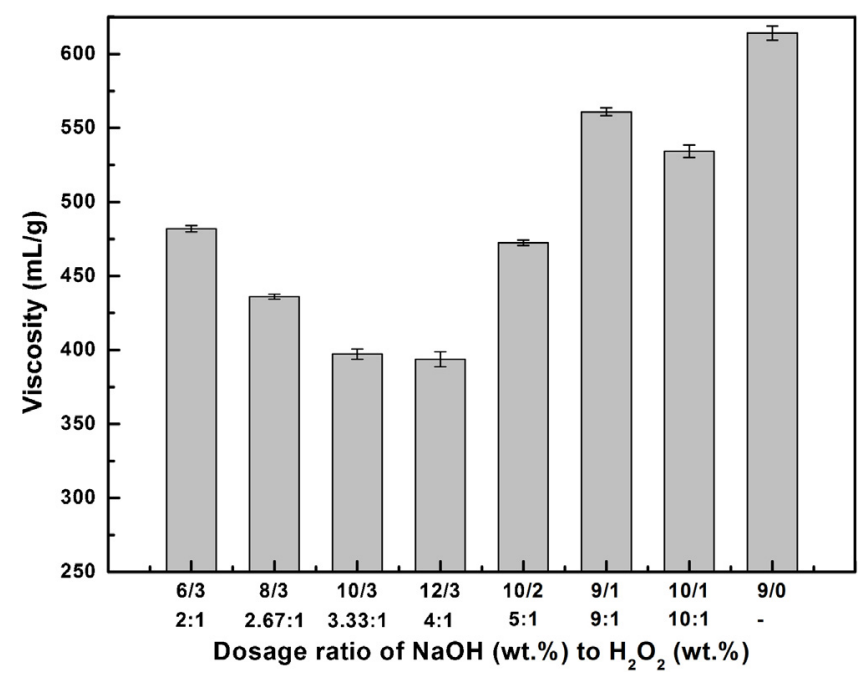

Fig. 5. Effects of alkaline peroxide treatment with different dosages of $\mathrm{NaOH}$ and $\mathrm{H}_{2} \mathrm{O}_{2}$ on pulp viscosity (alkaline peroxide treatment was conducted at $97^{\circ} \mathrm{C}$ for $1 \mathrm{~h}$ with 10 wt\% of pulp consistency and the certain dosages of $\mathrm{NaOH}$ and $\mathrm{H}_{2} \mathrm{O}_{2}$ ).

\subsection{Effects of alkaline peroxide treatment for enzymatic treated pulp}

Effects of alkaline peroxide treatment with different dosages of $\mathrm{NaOH}\left(\mathrm{wt} \%\right.$ ) and $\mathrm{H}_{2} \mathrm{O}_{2}$ (wt\%) on reactivity and $\alpha$-cellulose content were displayed in Fig. 4, while effects of alkaline peroxide treatment with different dosages of $\mathrm{NaOH}$ (wt\%) and $\mathrm{H}_{2} \mathrm{O}_{2}$ (wt\%) on pulp viscosity were shown in Fig. 5 . It was seen from Fig. 5 that, the pulp viscosity could be more easily adjusted by alkaline peroxide treatment compared to the alkali treatment with only $\mathrm{NaOH}$, and at the fixed dosage of $\mathrm{H}_{2} \mathrm{O}_{2}$ (3 wt\%), increasing the concentration of $\mathrm{NaOH}$ (from $6 \mathrm{wt} \%$ to $12 \mathrm{wt} \%$ ) led to remarkable reduction of pulp viscosity. This was due to the degradation of carbohydrates, and the formed radicals such as hydroxyl radical, hydroperoxy radical, as well as superoxide anion radical during alkaline peroxide treatment were responsible for the de-polymerization of cellulose and hemicellulose $[4,30]$. However, under such conditions, the reactivity decreased significantly, particularly at high dose of $\mathrm{NaOH}$ (over $8 \%$ ) with $3 \% \mathrm{H}_{2} \mathrm{O}_{2}$, as exhibited in Fig. 4. This might result from the hornification effect $[31,32]$, which was attributed to a reduced surface area and pore volume of pulps owing to the aggregation of microfibrils after the extraction of alkali soluble of hemicellulose and the degradation of carbohydrates. For example, after the alkaline peroxide treatment with $9 \% \mathrm{NaOH}$ and $1 \% \mathrm{H}_{2} \mathrm{O}_{2}$, the total reducing sugar in spent liquor of this stage of treatment was about $1.26 \mathrm{~g} / \mathrm{L}$. But such concentration of reducing sugar in spent liquor of alkaline peroxide treatment means only about $1-2 \%$ of sugar recovery could be achieved (based on the original dry pulp). Therefore, the sugar recovery for the spent liquor from the second stage will be ineffective and the spent liquor may go to chemical recovery system and waste water treatment system (well developed in the modern pulp industry) [4].

Fig. 5 also showed that, a higher pulp viscosity could be obtained at lower charge of $\mathrm{H}_{2} \mathrm{O}_{2}$ ( $2 \%$ or $1 \%$ ), which could avoid the excessive de-polymerization of cellulose, thus leading to a higher $\alpha$-cellulose content with appropriate reactivity (Fig. 4). Therefore, the suitable dosage of $\mathrm{NaOH}$ and $\mathrm{H}_{2} \mathrm{O}_{2}$ were $9 \%$ and $1 \%$, respectively, for the stage of alkaline peroxide treatment $\left(97^{\circ} \mathrm{C}\right.$ for $1 \mathrm{~h}$ with $10 \mathrm{wt} \%$ of pulp consistency) after the enzymatic treatment. Under these conditions, the resulting pulp with $92.1 \% \alpha$-cellulose content, $68.7 \%$ reactivity, and $506.9 \mathrm{~mL} / \mathrm{g}$ pulp viscosity could be obtained, which was comparable to the reference commercial dissolving pulp (reactivity of $68.8 \%$, $\alpha$-cellulose content of $89.9 \%$, and viscosity value of $499.7 \mathrm{~mL} / \mathrm{g}$ ). In addition, after the two stages of treatment, $79.8 \%$ of pulp yield could be achieved. The ash content and lignin content could be lower than $0.1 \%$ and $0.3 \%$, respectively. However, the key parameters ( $\alpha$-cellulose content, pulp reactivity and viscosity) of resulting pulp after the treatments with the reverse sequence i.e. alkaline peroxide treatment followed by enzymatic treatment, could not reach the requirement of dissolving pulp for viscose production (data not shown).

Therefore, by using cost effective EG-rich cellulase product and optimized alkaline peroxide treatment, dissolving pulp which satisfied the required parameters for viscose production could be obtained, and it is also possible to tailor the EG-rich cellulase based on the starting material (e.g. different species of pulp). The two stages of treatments (i.e. enzymatic treatment combined with alkaline peroxide treatment) are cost effective with lower environmental impacts compared with other methods. For instance, dilute acid treatment may cause equipment corrosion, thus limiting its application, and the one by using pure-EG is much more expensive [21].

Overall, based the results obtained above, further studies by developing a continuous process (enzymatic treatment followed by twin-screw extrusion-alkaline peroxide treatment) will be carried out in the near future, in that alkaline peroxide treatment can be performed at $97^{\circ} \mathrm{C}$ with good effect. The twin-screw process does not need extra heating device and is beneficial for the decrease of pulp viscosity as fibers can be modified during the extrusion process [24]. Also, the spent liquor can be recycled and reused for the twin-screw extrusion-alkaline peroxide treatment to minimize the environmental impacts, but the demonstration tests (including the further optimization of enzymatic treatment) for the entire process are needed as well.

\section{Conclusions}

In this preliminary research, two stages of treatments i.e. enzymatic treatment combined with alkaline peroxide treatment was performed to upgrade bleached softwood paper grade pulp to dissolving pulp for viscose production. The use of EG-rich cellulase in enzymatic treatment can significantly improve the pulp reactivity, and the quality of enzymatically treated pulp can be precisely adjusted by alkaline peroxide treatment with appropriate dosages of $\mathrm{NaOH}$ and hydrogen peroxide under certain conditions to reach the quality of dissolving pulp. Furthermore, the reducing sugar in 
the spent liquor derived from the stage of enzymatic treatment can be recovered for the production of value-added products based on the concept of biorefinery, and some related studies are under way.

\section{Acknowledgement}

Financial support was provided by the Natural Science Foundation of China (No. 21206184, 21306216 and No. 21201174), as well as the National High Technology Research and Development Program ("863” program) of China (No. 2012AA022301).

\section{References}

[1] V. Gehmayr, G. Schild, H. Sixta, A precise study on the feasibility of enzyme treatments of a kraft pulp for viscose application, Cellulose 18 (2011) 479-491.

[2] H. Li, A. Saeed, M.S. Jahan, Y. Ni, A. van Heiningen, Hemicellulose removal from hardwood chips in the pre-hydrolysis step of the kraft-based dissolving pulp production process, J. Wood Chem. Technol. 30 (2010) 48-60.

[3] H. Shi, P. Fatehi, H. Xiao, Y. Ni, A process for isolating lignin of pre-hydrolysis liquor of kraft pulping process based on surfactant and calcium oxide treatments, Biochem. Eng. J. 68 (2012) 19-24.

[4] H. Sixta, Handbook of Pulp, Wiley-VCH Verlag GmbH \& Co. KGaA, Weinheim, Germany, 2006.

[5] D. Ibarra, V. Köpcke, P.T. Larsson, A.S. Jääskeläinen, M. Ek, Combination of alkaline and enzymatic treatments as a process for upgrading sisal paper-grade pulp to dissolving-grade pulp, Bioresour. Technol. 101 (2010) 7416-7423.

[6] N. Kvarnlöf, U. Germgård, L.J. Jönsson, C.A. Söderlund, Optimization of the enzymatic activation of a dissolving pulp before viscose manufacture, Tappi J. 6 (6) (2007) 14-19.

[7] G. Henriksson, M. Christiernin, R. Agnemo, Monocomponent endoglucanase treatment increases the reactivity of softwood sulphite dissolving pulp, J. Ind. Microbiol. Biotechnol. 32 (2005) 211-214.

[8] V. Köpcke, D. Ibarra, P.T. Larsson, M. Ek, Optimization of treatment sequences for the production of dissolving pulp from birch kraft pulp, Nord. Pulp Pap. Res. J. 25 (1) (2010) 31-38.

[9] H.A. Krässig, Cellulose: Structure, Accessibility and Reactivity, Gordon and Breach Science Publishers, Yverdon, Switzerland, 1993.

[10] L. Rahkamo, L. Viikari, J. Buchert, T. Paakkari, T. Suortti, Enzymatic and alkaline treatments of hardwood dissolving pulp, Cellulose 5 (1998) 79-88.

[11] V. Gehmayr, H. Sixta, Pulp properties and their influence on enzymatic degradability, Biomacromolecules 13 (2012) 645-651.

[12] D. Ibarra, V. Köpcke, M. Ek, Exploring enzymatic treatments for the production of dissolving grade pulp from different wood and non-wood paper grade pulps, Holzforschung 63 (2009) 721-730.

[13] L.S. Jackson, J.A. Heitmann, T.W. Joyce, Production of dissolving pulp from recovered paper using enzymes, Tappi J. 81 (3) (1998) 171-178.

[14] Y. Nishiyama, P. Langan, H. Chanzy, Crystal structure and hydrogen-bonding system in cellulose $\mathrm{I} \beta$ from synchrotron X-ray and neutron fiber diffraction, J. Am. Chem. Soc. 124 (2002) 9074-9082.
[15] Z. Liu, P. Fatehi, S. Sadeghi, Y. Ni, Application of hemicelluloses precipitated via ethanol treatment of pre-hydrolysis liquor in high-yield pulp, Bioresour. Technol. 102 (2011) 9613-9618.

[16] B. Li, H. Li, Q. Zha, R. Bandekar, A. Alsaggaf, Y. Ni, Review: effects of wood quality and refining process on TMP pulp and paper quality, BioResources 6 (3) (2011) 2569-3584.

[17] R. Chandra, R. Singh, Decolourisation and detoxification of rayon grade pulp paper mill effluent by mixed bacterial culture isolated from pulp paper mill effluent polluted site, Biochem. Eng. J. 61 (2012) 49-58.

[18] L.R. Lynd, P.J. Weimer, W.H. van Zyl, I.S. Pretorius, Microbial cellulose utilization: fundamentals and biotechnology, Microbiol. Mol. Biol. Rev. 66 (3) (2002) 506-577.

[19] V. Köpcke, D. Ibarra, M. Ek, Increasing accessibility and reactivity of paper grade pulp by enzymatic treatment for use as dissolving pulp, Nord. Pulp Pap. Res. J. 23 (4) (2008) 363-368

[20] A.C. Engström, M. Ek, G. Henriksson, Improved accessibility and reactivity of dissolving pulp for the viscose process: pretreatment with monocomponent endoglucanase, Biomacromolecules 7 (2006) 2027-2031.

[21] M. Vehviläinen, T. Kamppuri, P. Nousiainen, A. Kallioinen, M. Siika-Aho, K.E. Christoffersson, M. Rom, J. Janicki, Effect of acid and enzymatic treatments of TCF dissolving pulp on the properties of wet spun cellulosic fibers, Cell. Chem. Technol. 44 (4-6) (2010) 147-151.

[22] Z. Qiu, Y. Ni, S. Yang, Using DTPA to decrease manganese-induced peroxide decomposition, J. Wood Chem. Technol. 23 (1) (2003) 1-11.

[23] L. Yu, M. Rae, Y. Ni, Formation of oxalate from the $\mathrm{Mg}(\mathrm{OH})(2)$-based peroxide bleaching of mechanical pulps, J. Wood Chem. Technol. 24 (4) (2004) 341-355.

[24] C. Liu, E. van der Heide, H. Wang, B. Li, G. Yu, X. Mu, Alkaline twin-screw extrusion pretreatment for fermentable sugar production, Biotechnol. Biofuels 6 (2013) 97, http://dx.doi.org/10.1186/1754-6834-6-97.

[25] W. Fock, A modified method for determining the reactivity of viscose-grade dissolving pulps, Papier 13 (1959) 92-95.

[26] K.E. Christoffersson, M. Sjöström, U. Edlund, Å. Lindgren, M. Dolk, Reactivity of dissolving pulp: characterisation using chemical properties, NMR spectroscopy and multivariate data analysis, Cellulose 9 (2) (2002) 159-170.

[27] S. Zhou, S. Yao, M. Xing, J. Pu, Applied study of birch pulp bleaching using dimethyldioxirane to obtain acetate-grade pulp, BioResources 5 (3) (2010) 1779-1788.

[28] J. Shen, P. Fatehi, P. Soleimani, Y. Ni, Recovery of lignocelluloses from pre-hydrolysis liquor in the lime kiln of kraft-based dissolving pulp production process by adsorption to lime mud, Bioresour. Technol. 102 (2011) 10035-10039.

[29] J. Shen, P. Fatehi, P. Soleimani, Y. Ni, Lime treatment of prehydrolysis liquor from the kraft-based dissolving pulp production process, Ind. Eng. Chem. Res. 51 (2) (2012) 662-667.

[30] Y. Ni, G. Kang, Formation of peracetic acid during peroxide bleaching of mechanical pulp, Appita J. 60 (2007) 70-73.

[31] G. Jayme, E. Roffael, Die auswirkung verschiedener alkalischer veredelungsbedingungen auf das verhalten von zellstoffen bei der acetylierung, Das Papier 3 (1949) 469-476.

[32] B. Kyrklund, H. Sihtola, On structural changes in pulp fibres due to cold alkali treatment, Paper och Trä 4 (1963) 131-134. 